\title{
Sacro-Coccygian Teratoma: About a Case Reported in a Context with a very Limited Technical Plate in Yakoma, Nord-Ubangi, Democratic Republic of Congo
}

\author{
Gaspard Makambo Mohilo1 ${ }^{*}$, Vincent Danvene Gonda ${ }^{2}$, Maurice Masoda Nyamalyongo ${ }^{3}$ \\ ${ }^{1}$ Family Medicine, Protestant University in Congo, Goma, Democratic Republic of Congo \\ ${ }^{2}$ Department of Pediatrics, Yakoma General Hospital, Gbadolite, Democratic Republic of Congo \\ ${ }^{3}$ Department of Family Medecine, Heal Africa Hospital, Goma, Democratic Republic of Congo \\ Email: *makambogaspard@gmail.com
}

How to cite this paper: Mohilo, G.M., Gonda, V.D. and Nyamalyongo, M.M. (2021) Sacro-Coccygian Teratoma: About a Case Reported in a Context with a very Limited Technical Plate in Yakoma, Nord-Ubangi, Democratic Republic of Congo. Open Access Library Journal, 8: e7084.

https://doi.org/10.4236/oalib.1107084

Received: December 15, 2020

Accepted: February 23, 2021

Published: February 26, 2021

Copyright $\odot 2021$ by author(s) and Open Access Library Inc.

This work is licensed under the Creative Commons Attribution International License (CC BY 4.0).

http://creativecommons.org/licenses/by/4.0/

\begin{abstract}
Sacrococcygeal teratoma is a very rare but often malignant congenital embryonic tumor. We report a case in an infant $\mathrm{X}$ aged 5 months, born eutocically in a pregnancy estimated at term. It was a third gesture, two parities and an abortion, a pregnancy punctuated by several episodes of illnesses not elucidated by her mother until childbirth. Due to the lack of a technical platform, the infant was not taken care of.
\end{abstract}

\section{Subject Areas}

Pediatrics

\section{Keywords}

Sacrococcygeal Teratoma, Case Reported, Context with a very Limited Technical Plate

\section{Introduction}

Sacrococcygeal teratoma is a rare disease, most often benign. Although rare, it remains the most common tumor in the caudal region of children with an estimated incidence of $1 / 35,000$ to $1 / 4000$ births, it affects girls 4 times more than boys [1] [2] [3] [4].

A presacral mass may be congenital or developmental or may result from inflammation. The lump can have neural, vascular, lymphatic, or mesenchymal 
origins and can be primary (as in focal disease) or systemic (as in multifocal disease) [1].

Regarding its classification, according to the Surgery Section of the American Academy of Pediatrics, clinical classification is a good prognostic indicator of sacrococcygeal teratomas [5]. Tumors are divided into 4 types [5]:

- Type I: predominantly external tumor with minor presacral development;

- Type II: externally developing tumor with a significant intra-pelvic part;

- Type III: apparently external tumor but with predominant pelvic and abdominal development;

- Type IV: pre-sacral tumor without external development.

Symptoms of the mass effect can lead to constipation, pain in the sacrococcygeal region, bladder dysfunction, venous engorgement of the lower extremities, and neurological symptoms [6] [7] [8] [9].

Medical imaging plays a vital role in diagnosis; standard radiography, ultrasound, computerized tomography (CT), and MRI (magnetic resonance imaging) are used to characterize the mass, assess intra-pelvic extension, and assess the relationship of the mass to other structures [6].

For treatment, surgical excision is the standard of care and usually results in a cure, with histopathological confirmation of the diagnosis [8].

\section{Case Report}

A 5-month-old female infant with a buttock lump with difficulty in sitting, born eutocically from a pregnancy estimated to be full term. In the maternal history, she third gesture, two parities and had an abortion, her pregnancy was marked by several episodes of unsolved illnesses until the childbirth.

After our assessment, we observed a gluteal mass of more or less hard consistency of about $8 \mathrm{~cm}$ in diameter (Figure 1 and Figure 2). For lack of technical platform, only the ultrasound of this mass was done showing mixed echogenicity (Figure 3). The patient was referred for better management by a pediatric surgical team.

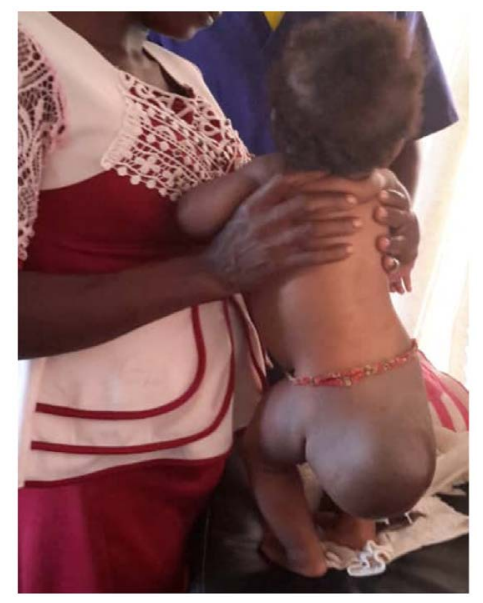

Figure 1. Posterior presentation of the mass in the gluteal region. 


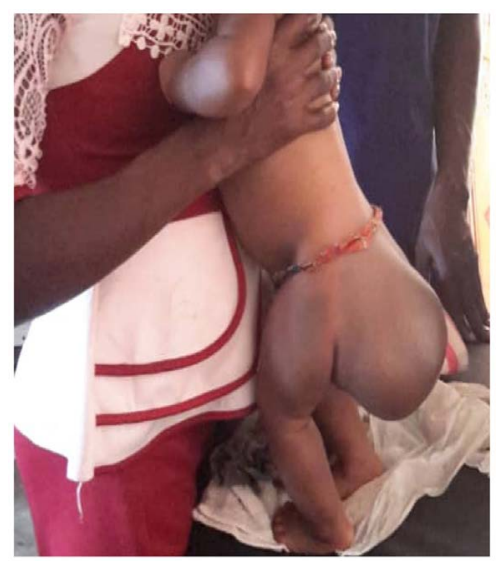

Figure 2. Lateral presentation of the mass in the gluteal region.

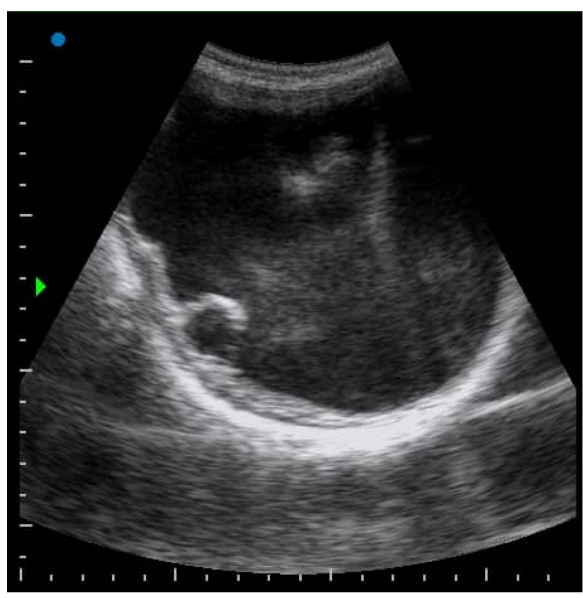

Figure 3. Mixed echogenicity.

\section{Discussion and Conclusions}

The patient presents with a classic sacrococcygeal teratoma, probably type II or III [5]. Even if we clinically concluded this, only medical imaging (MRI) can help us properly classify the mass and even see its extension [6]. MRI determines the tumor composition: cyst, fat, and calcifications; also allows: to locate the teratoma in relation to the pelvic organs, in particular the rectum and the bladder; and to delimit the pelvic bone structures therefore to show the coccygeal attachment; and identifies small endopelvic extensions that may have escaped ultrasound [10] [11] [12].

Surgical excision is the standard of care and usually results in a cure, with histopathological confirmation of the diagnosis [8].

In the absence of adequate care, there is a risk of a switch from benignity to malignancy.

\section{Conflicts of Interest}

The authors declare no conflicts of interest regarding the publication of this paper. 


\section{References}

[1] Kocagogbu, M. and Frush, D.P. (2006) Pediatric Presacral Masses. RadioGraphics, 26, 833-857. https://doi.org/10.1148/rg.263055102

[2] Keslar, P., Buck, J.L. and Suarez, E.S. (1994) Germ Cell Tumors of the Sacrococcygeal Region: Radiogic-Pathologic Correlation. RadioGraphics, 14, 607-620. https://doi.org/10.1148/radiographics.14.3.8066275

[3] Wells, R.G. and Sty, J.R. (1990) Imaging of Sacrococcygeal Germ Cell Tumors. RadioGraphics, 10, 701-713. https://doi.org/10.1148/radiographics.10.4.2165626

[4] Jamaleddine, Z., et al. (2010) Childhood Pelvic Tumors. JFR.

[5] Colleen, F., Swayze, M., Thomas, C. and Wheeler, H. (1994) Sacrococcygeal Teratoma. http://www.thefetus.net

[6] Shatnawi, N.J., Khammash, M.R. and Omari, A.H. (2019) A Giant Sacrococcygeal Teratoma in Adult Female: A Case Report. International Journal of Surgery Case Reports, 54, 47-50. https://doi.org/10.1016/j.ijscr.2018.11.039

[7] Ng, E.W., Porcu, P. and Loehrer, P.J. (1999) Sacrococcygeal Teratoma in Adults: Case Reports and a Review of Literature. Cancer, 86, 1198-1202. https://doi.org/10.1002/(SICI)1097-0142(19991001)86:7<1198::AID-CNCR14>3.0.C O;2-M

[8] Goyal, A., Rathod, P.S., Reddihalli, P.V., Krishnappa, S., Rajshekar, S.K., Kansal, Y., et al. (2020) A Rare Case of Sacrococcygeal Teratoma in Adult. Indian Journal of Surgical Oncology, 11, 102-104. https://doi.org/10.1007/s13193-020-01047-0

[9] Diaz-Aguilar, D., Terterov, S., Scharnweber, R., Merna, C., Wang, S. and Rahman, S. (2017) Adult Sacrococcygeal Teratoma with Coccygectomy: A Case Report with a Review of the Literature. Surgical Neurology International, 8, 260.

http://surgicalneurologyint.com/surgicalint-articles/adult-sacrococcygeal-teratomawith-coccygectomy-a-case-report-with-a-review-of-the-literature/ https://doi.org/10.4103/sni.sni 22417

[10] VK, K., Jadhav, A., Gupta, A., Shukla, A.K., Chaturvedi, V. and Kundal, R. (2015) Sacrococcygeal Teratoma: Experience with 36 Patients in a Teritiary Care Hospital. Journal of Nepal Paediatric Society, 35, 89-93.

https://doi.org/10.3126/jnps.v35i1.10945

[11] Friederich, L., Diguet, A., Eurin, D., Bachy, B., Roman, H., Marpeau, L. and Verspyck, E. (2007) Sacrococcygeal Teratoma of the Size of the Fetus: Antenatal Surveillance, Fetal Therapy in Utero and Obstetrical Management. Gynécologie Obstétrique \& Fertilité, 35, 1001-1004. https://doi.org/10.1016/j.gyobfe.2007.07.030

[12] Ali Mahmoud, M.D., Nadia, F. and Mahmoud, M.D. (2007) Prenatal and Neonatal MRI of Sacrococcygeal Teratoma with Surgical Correlation. Radiology Case Reports, 2, 287-290. https://doi.org/10.2484/rcr.v2i3.91 